\title{
Immunohistochemical Evaluation of Hemostatic Changes in Glioblastoma Multiforme and Low-Grade Astrocytoma
}

\author{
Ersin HACIYAKUPOGLU1', Dervis Mansuri YILMAZ², Jan WALTER ${ }^{3}$, Seyda ERDOGAN ${ }^{4}$, \\ Sebahattin HACIYAKUPOGLU ${ }^{5}$, Susanne A KUHN³ \\ ${ }^{1}$ Heinrich-Braun-Clinic, Department of Neurosurgery, Zwickau, Germany \\ ${ }^{2}$ Cukurova University, School of Medicine, Balcali Hospital, Department of Neurosurgery, Adana, Turkey \\ ${ }^{3}$ Friedrich- Schiller University, Department of Neurosurgery, Jena, Germany \\ ${ }^{4}$ Cukurova University, School of Medicine, Balcali Hospital, Department of Pathology, Adana, Turkey \\ ${ }^{5}$ Acibadem Adana Hospital, Neurosurgery Clinic, Adana, Turkey
}

Corresponding author: Dervis Mansuri YILMAZ mansuriyilmaz@gmail.com

\section{ABSTRACT}

AIM: To compare glioblastoma multiforme with astrocytoma grade II by subjectively evaluating the levels of prothrombin and biotinylation thrombin, and G protein serum protease activatin receptors, as tissue factors causing hypercoagulation and affecting coagulation.

MATERIAL and METHODS: Specimens from 35 cases with glioblastoma multiforme and 23 cases with astrocytoma grade II were evaluated immunohistochemically. The specimens were stained with hematoxylen-eosin and immunohistochemically for prothrombin, biotinylation thrombin and protease activating factor receptors to determine the correlation between the tumor malignancy and coagulation factor receptors.

RESULTS: An increase in malignancy was seen to result in an increase in prothrombin, biotinylation thrombin, protein activator receptor 1 , protein activator receptor 3 , and protein activator receptor 4 levels, and a decrease in protein activator receptor 2 level. These data showed that there was hypercoagulability in glioblastoma multiforme. Descriptive statistics and Mann-Whitney $U$ analysis were used to evaluate the results.

CONCLUSION: In glioblastoma multiforme with no radiological evidence of hemorrhage, low molecular weight heparin should be administered peroperatively and continued for 3 months postoperatively to prevent the development of deep venous thrombosis. This will also be useful in the prevention of invasion, angiogenesis, metastasis and tumour progression.

KEYWORDS: Gliblastoma multiforme, Astrocytoma, Prothrombin, Thrombin, Protein activator receptor, Hypercoagulability

\section{INTRODUCTION}

$\mathrm{I}$ $\mathrm{n}$ healthy individuals, there is hemostatic balance between procoagulation activity and anticoagulant and fibrinolytic activities. To achieve this balance, there has to be harmonious activity of tissues, vessels, thrombocytes and plasma factors. There is a link between tumour cells and the hemostatic system, formed by the expressions of tumour necrosis factor (NF), interleukin-1 (IL $)$ growth factor (GF) procoagulant calcium-dependent cystein, protease activators (PA), heparinase, and proteolytic enzymes. These stimuli that are formed mostly of cytokines and GF activate their own tumour cells by stimulating microglia, endothelial cells, coagulation factors and thrombocytes, and several stimulants that affect the hemostatic system, tumour growth, invasion and the immunological system are expressed from these tissues $(5,6,9,22)$.

In invasive, proliferative, destructive, infiltrative, malignant tumours, such as glioblastoma multiforme (GBM), the balance
Ersin HACIYAKUPOGLU (D) : 0000-0003-3836-4718

Dervis Mansuri YILMAZ (1D): 0000-0002-5137-4526

Jan WALTER (10): 0000-0003-0890-5544

$\begin{array}{ll}\text { Seyda ERDOGAN } & \text { (1) : }: 0000-0002-4113-2080 \\ \text { Sebahattin HACIYAKUPOGLU } & \text { (1) : } 0000-0002-5236-7088 \\ \text { Susanne A KUHN } & \text { (D) : } 0000-0002-2495-068 X\end{array}$


in coagulation is impaired towards hypercoagulability, associated with chronic hemostatic activation. Therefore, deep venous thromboembolism (VTE) seen at the rate of $19 \%$ in GBM has been reported to affect mortality at the rate of $17 \%$ $(10,19,22,28)$.

GBM is invasive to the brain at a Newtonian mechanical force of $60 \mathrm{~m} \mu / \mathrm{hr}$. While brain tissue responds to this action, an acute hemodynamic change, necrosis, angiogenesis, inflammation, oedema, hypoxia and electrolyte impairment occur. Also in the brain tissue, Tissue factors (TF) emerge in the PA structure. These substances, the majority of which are procoagulant, comprise prothrombin, thrombin, fibrin, coagulation factors, vascular endothelial growth factor (VEGF), substance P, cytokines, D-dimer fibrin fragmentation product, fibrin monomers, $C$ reactive protein, PL selectin, TAT, and fibro peptide A. For PA to be able to be active in the form of $\mathrm{G}$ protein, protease-activated receptor (PAR) binding is necessary $(3,11,12,14,28)$.

The aim of this study was to evaluate PAR I (PAR 111 and ATAP), PAR 2, PAR 3, PAR 4, prothrombin and biotinylation thrombin values, which cause hypercoagulability, in the specimens of 35 GBM and 23 astrocytoma grade II cases, through subjective grading by 2 pathologists and to discuss the extent of the contribution to hemostasis.

\section{MATERIAL and METHODS}

This study was approved by the Ethics Committee and the Scientific Research Projects Fund of Uniklinikum Jena University (Project number: 2056-06/07). All the tissue samples were fixed in $10 \%$ formaldehyde for 24 hours. Then tissue pieces were washed with water to remove the formaldehyde and dehydrated in graded ethanols. Afterwards, the tissue samples were immersed in xylol series and melted paraffin solution. The tissue samples were then embedded in paraffin. About $5 \mu \mathrm{m}$ thick tissue sections were taken the paraffin tissue blocks and stained with hematoxylin and eosin.

Table I: Staining Score

\begin{tabular}{lcc}
\hline Staining & Value & Explanation \\
\hline Negative & 0 & No staining \\
\hline Mild & 1 & Mild staining \\
\hline Moderate & 2 & Moderate staining \\
\hline Good & 3 & Well staining \\
\hline
\end{tabular}

Five $\mu \mathrm{m}$ thickness paraffin sections were prepared for immunohistochemical analysis with the Ventana fully automated immunostainer for anti-prothrombin, biotinylation thrombin, PAR 111, ATAP, PAR 2, PAR 3, PAR 4 antibodies.

Fifty eight cases were diagnosed as GBM (35 cases) and grade II astrocytoma (23 cases) by two specialist neuropathologists.

Evaluation of staining score: On the hematoxylin-eosin-stained slides, 10 random fields $\left(\mathrm{HPF}=0.16 \mathrm{~mm}^{2}\right)$ were selected and graded on a scale from 0 to 3 at magnification of $x 10, x 20$, and $x 40$ (Table I). The same process was applied to the other immunohistochemically stained slides for coagulation factor receptors and the mean value of the 10 fields was estimated.

\section{Statistical Analysis}

SPSS for Windows software was used in order to manage data and perform statistical analysis. Descriptive statistics and Mann-Whitney $U$ analysis were used to evaluate the results. The level of $p<0.05$ was considered to be statistically significant.

\section{RESULTS}

The values of prothrombin, ATAP, biotinylation thrombin and PAR levels are shown in Table II. The prothrombin, biotinylation thrombin, ATAP, and PAR3 levels were found to be increased in high grade GBM. The PAR 4 level was not found to be high and the PAR 2 level was low (Figures 1A-F; 2A-F; 3A-D). The results of this study demonstrated that high grade gliomas could trigger hemostatic mechanisms in favor of coagulation.

\section{DISCUSSION}

An anti-thrombin layer is formed by coverage of the endothelium surface with proteoglycans composed of heparin, heparin sulphate and dermatan sulphate at a thickness of 55 $A^{\circ}$. Despite an excellent balance between the clotting system and the plasminogen/plasmin activator system, each day approximately 2000 arterioles, venules and capillaries are torn, are obstructed with thrombus, bleeding is stopped, and they are covered with fibrin and remodelling occurs. The fibrinolytic system actively provides recanalisation and reperfusion $(7,13,15,18,29)$.

During invasion of the GBM to the brain tissue, in addition to the change in regional parenchyma, and TFs emerging from the brain tissue, tumour cells express TNF, IL ${ }_{1}$, interferon (IFN), VEGF, and T-cell suppressing transforming GF (TGF). These factors provoke angiogenesis, invasion and prothrombic

Table II: Summary of Specimens

\begin{tabular}{lcccccccc}
\hline Preparate & $\mathbf{N}$ & Prothr. & Biothr & ATAP & $\mathbf{1 1 1}$ & PAR2 & PAR3 & PAR4 \\
\hline Glioblastoma multiforme & $\mathbf{3 5}$ & $1.460 \pm .69$ & $1.45 \pm 0.55$ & $1.94+-0.70$ & $1.57 \pm 0.56$ & $0.84 \pm 0.35$ & $1.47 \pm 0.39$ & $1.33 \pm 0.35$ \\
\hline Astrocytoma, Grade II & $\mathbf{2 3}$ & $0.66 \pm 0.46$ & $1.08 \pm 0.53$ & $0.67 \pm 0.78$ & $1.47 \pm 0.78$ & $1.07 \pm 0.55$ & $1.14 \pm 0.73$ & $1.33 \pm 0.65$ \\
\hline & & $\mathbf{p}<0.001$ & $\mathbf{p}=\mathbf{0 . 0 0 2}$ & $\mathbf{p}<0.001$ & $\mathrm{p}=0.993$ & $\mathbf{p}=\mathbf{0 . 0 0 2}$ & $\mathrm{p}=0.993$ & $\mathrm{p}=1.000$ \\
\hline
\end{tabular}

Prothrombin (Proth), Biolated thrombin (Bioth), Protease receptor PAR 1 (ATAP, PAR 111), PAR 2, PAR3, PAR 4) values are expressed as the mean +- SEM. 
changes. The tumour cell together with protein G, which causes hypercoagulation, has fibrinolytic activity expressed from the endothelium and invasive brain tissue, suppresses protein $\mathrm{C}$, and the tumour cells are surrounded by fibrin deposits. Fibrin protects the tumour cells from immunological dangers, supports the tumour matrix and stroma and facilitates tumour progression.

These factors composed of GF and cytokines expressed from tumour cells, also cause hypercoagulability together with
TFs by stimulating endothelium, monocytes, macrophages, microglia, platelets and coagulation factors. GBMs express some microparticles with procoagulation activity on the cell surface, one of which is anexin II. This leads to hypercoagulation by binding to plasminogen and its plasma activators, and the other is calcium-dependent cystein, which provokes coagulation by directly activating $\mathrm{FX}(1,9,10,19,25,28)$.

GBMs express endotoxins and cytokines, and to compensate for thrombin activators, these substances stimulate the
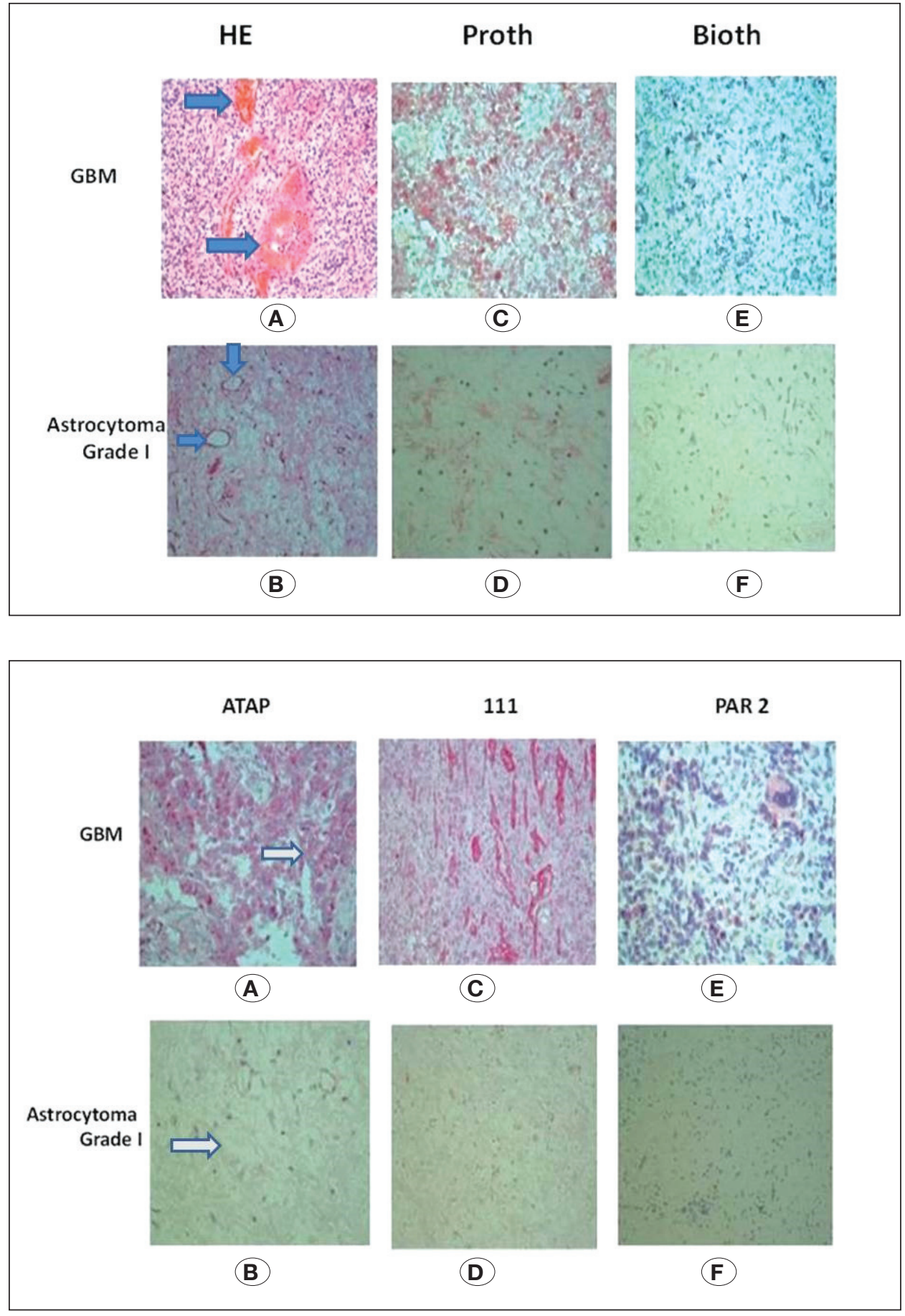

Figure 1: A) Vascular proliferation and hemorrhage in GBM (HE x200), B) blood vessels in low grade astrocytoma. (HE x100), C-E) strong prothrombin and moderate expression of biotinylation thrombin respectively in GBM. (immunohistochemistry x200). D-F) Weak expression in low grade astrocytoma (immunohistochemistry x200).

Figure 2: A) Pleomorphic cells in GBM. (ATAP) (immunohistochemistry x200). B) Low cellular areas in low grade astrocytoma. (ATAP) (immunohistochemistry $\times 200$ ). C-E) Strong positivity with PAR 111 and PAR 2 in GBM. (immunohistochemistry $x 200$ ). D-F) Weak expression with PAR 111 and PAR 2 in low grade astrocytoma (immunohistochemistry $\mathrm{x} 200$ ). 


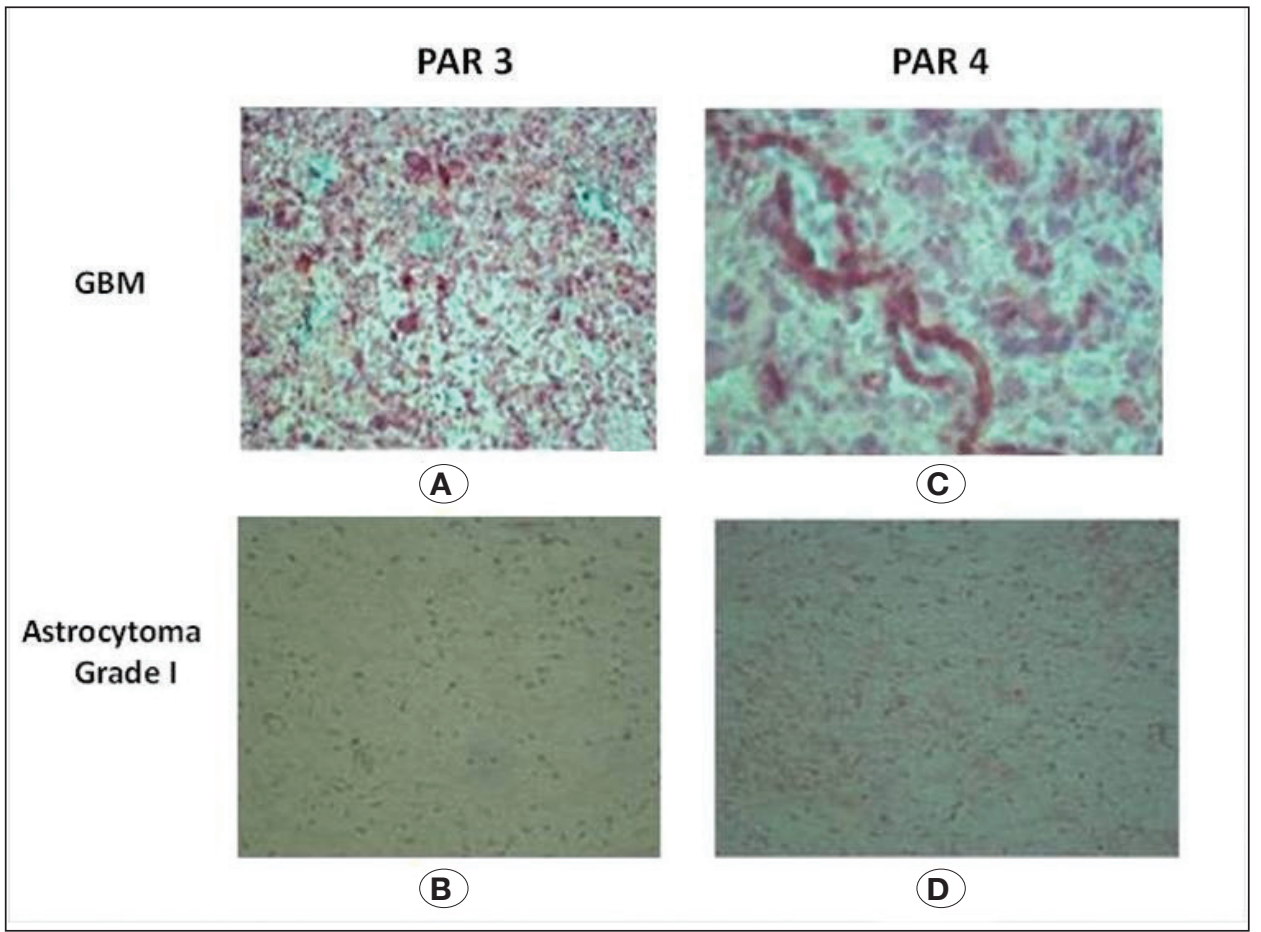

Figure 3: A-C) Strong positivity with PAR 3 and PAR 4 in GBM. (immunohistochemistry $\times 200$ ) and (immunohistochemistry $x 400$ ). B-D) Weak expression with PAR 3 and PAR 4 in low grade astrocytoma (immunohistochemistry $\times 200$ ). expression from the endothelium of tissue plasminogen activator (tPA) and urinary plasminogen activator (UPA) in the composition of protein $\mathrm{C}$. When blood levels increase, these are neutralised with down-regulation, by expressing endothelial plasminogen activator inhibitor (PAI) and thrombo modulin, which bind to IPA and UPA. In addition, the remaining TPA is neutralised by alpha 2 antiplasma synthesised from the liver, and the hypercoagulability state continues. Therefore, VTE is seen in patients months before a diagnosis of malignancy is made $(5,9,19,20)$.

The TNFs expressed by GBM and the activated platelets and cytokines form micro thrombi with the help of leukocytes by surrounding the tumour cells in the vascular bed with fibrin. Adhesion molecules expressed from active endothelium bind to these micro thrombins and thus the tumour cells are protected from immunological attack and are both extravasive and invasive to tissue.

In platelets stimulated over a long period, clonal abnormalities emerge. ADP, Von Willebrandt protein, and thrombaxane A2 synthesis increases and these accelerate myeloproliferative activity and thrombin generation.

Active platelets contribute to tumour adhesion and invasion as PL selectin is expressed from endothelial cells and monocytes, and these regulate the interaction between platelets and leukocytes $(10,17,20,26,30)$.

GBM, glial and endothelial cells are rich in PAR, so the prothrombin, thrombin and PAR values in the specimens were measured subjectively with the immunocytochemistry method in the determination of the coagulation activity of astrocytoma grade II and GBM. For each specimen, the mean value of 10 separately examined areas was taken.
PAR 111, ATAP, PAR2 and PAR3 are activated with thrombin, and PAR4 with thrombin and trypsin. In tumour invasion, trauma and thrombus, PAR synthesis is accelerated with glial fibrillary acidic protein. This stimulates the active thrombin coagulation cascade and provides vascular remodelling, recanalisation and wound repair. It also stimulates GF expression, and activates phospholipase C. Together with adenyl cyclase, actin and protein kinase $\mathrm{C}$, this creates a mitogenic effect in the endothelium, smooth muscle and fibroblasts, and as more proliferative in the endothelium than PAR 1-2, these hypercoagulant substances are expressed more.

GBM has multilinear differentiation, a heterogenetic structure and multiple antigenity. Therefore, even within a single preparate, the PAR amount is highly variable. Prothrombin, biotinylation thrombin, ATP and PAR 3 are much higher in GBM than in astrocytoma grade II, and when malignancy increases, the amounts also increase. PARA4 is a little higher in GBM than in astrocytoma and PAR 2 is lower in GBM than in astrocytoma grade II. PAR2 has a cross-effect with other PARs $(2,3,8,14,21,23)$.

ATAP is a PAR1 product for which fibroblasts and thrombin are responsible. It may be activated with plasmin, cathepsin, cytotoxic T-cell, converting enzyme and angiotensin. Moreover, the affinity to thrombin is extremely high and it is easily activated.

PAR3 values are very close to those of astrocytoma grade II. This is because angiogenic activity is 50 -fold greater in GBM and a high degree of VEGF is expressed. There are extremely angiogenic vessels, and lymph nerves, basal lamina, laminin and fibronectin are not found in these vessels. PAR3 does not become active by binding to laminin and therefore the value 
is close to astrocytoma grade II which has extremely low vascularity.

PAR2 is found in the gastrointestinal tract, the kidneys, liver, endothelium, smooth muscle, T lymphocyte and tumour cells. It is activated with tryptase expressed from the pancreas. It plays a role in smooth muscle activity, gastrointestinal motility, blood flow and inflammation. It is regulated with TNF an $\mathrm{IL}_{1}$, and is low in GBM because contact with microglia and macrophages is low for protection against immunological attack, and therefore for PAR 2 to be active there must be no trypsin and tryptase in the environment $(4,21,23,28,30)$.

Rodas et al. stated that TF and procoagulant factors were extremely high and there was VTE in the glioma of the pathological specimens of the majority of patients where intra-tumoral thrombus was seen (27) (Figure 4).

Kayser-Gatchalian and Kayser determined VTE in mean $31 \%$ of patients in GBM (16). Moreover, the cancer grade, chemotherapy, radiotherapy, age, gender, obesity fever,

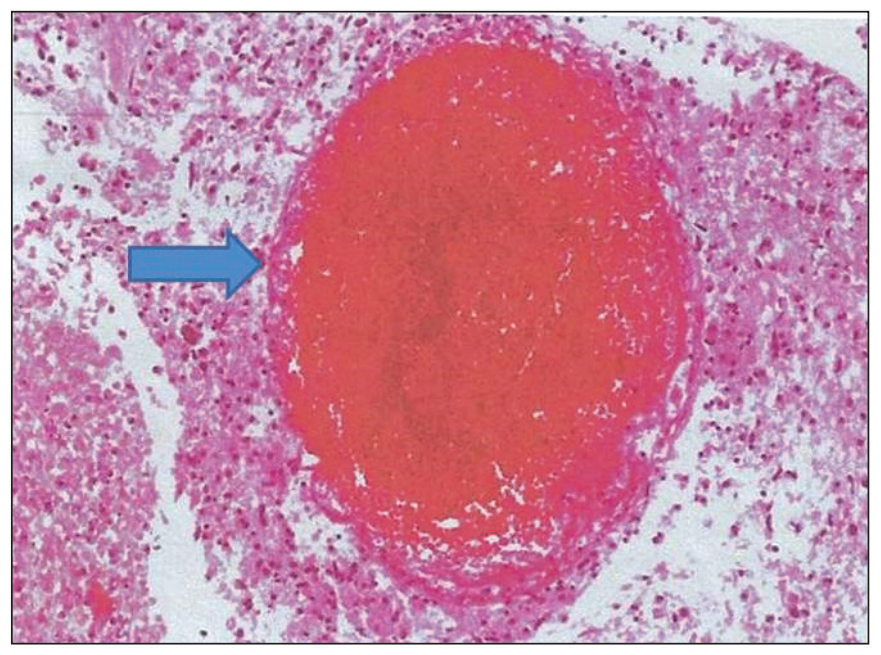

Figure 4: Thrombus mass in the dilated vessel of GBM (HE x200). leukocytosis, infection, lung and kidney diseases, platelets $>350,0000 / \mathrm{cc}$, duration of the operation, length of stay in hospital and blood transfusion increased the rate of VTE $(4,18,19,24)$.

Despite hypercoagulability, bleeding may be seen within and around the tumour in GBM. The reasons for this are; 1) thin walls do not have the capacity to contract, 2) GBM expresses neutral cyalic acid which fragments neomidase that destroys vessel walls, phospholipase $\mathrm{G}$ which provides tumour cell movement, collagenase which destroys collagens, and cysteinase enzyme which is a plasminogen activator, 3) it causes stasis by compressing tumour venous structures, and in acute decompresssion bleeding occurs in the bed (Figure $5 A$, B) $(7,9,14,26)$.

There is a tendency to hypercoagulation in tumours of the ovary, breast, pancreas, stomach, kidney, lung and hematopoietic system. Therefore, taking into account choriocarcinoma, thyroid, renal cell, malignant melanoma, bladder tumour and disseminated adenocarcinoma metastasis in which a high incidence of hemorrhage is seen, even if there are no radiological findings of bleeding, low-molecular weight heparin should certainly be used per-operatively and for at least 3 months postoperatively in brain tumours. In addition to the prevention of VTE, anticoagulant treatment is effective in the prevention of tumour progression, invasion, metastasis and angiogenesis $(12,18,19,22)$.

\section{CONCLUSION}

It can be recommended that anticoagulant therapy may be effective in preventing progression, invasion, metastasis, and angiogenesis of the tumor besides inhibiting VTE.

\section{REFERENCES}

1. Bauer AK, Leung KLL, Tirnaver SJ: Pathogenesis of the hypercoagulable state associated with malignancy. UpToDate 1-8, 2013

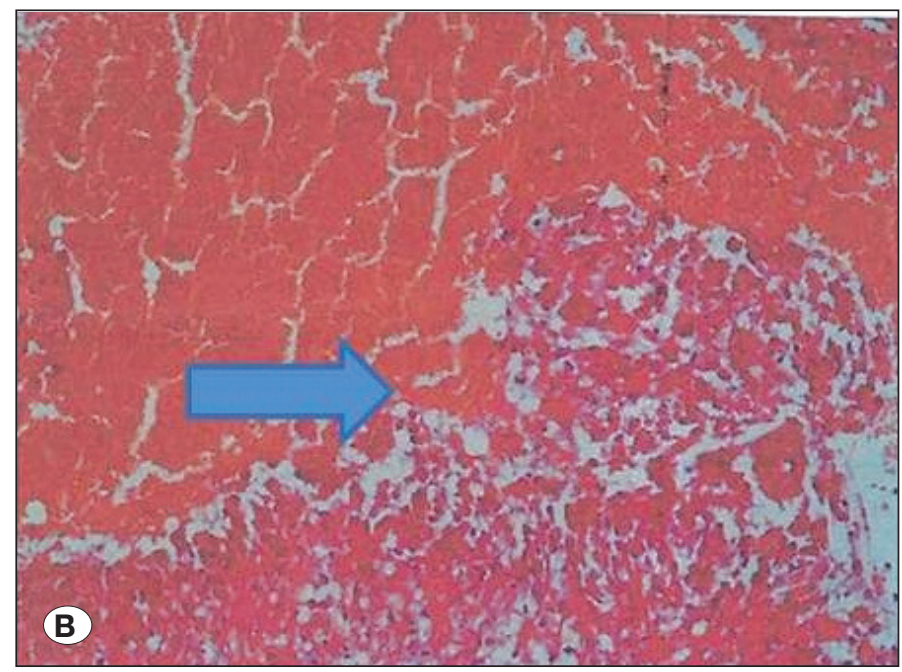

Figure 5: A) Vascular stasis in GBM (HE x200). B) Bleeding in GBM (HE x200). 
2. Bohem SK, McConalogue K, Kong W, Bunnett WN: Proteinaseactivated receptors. Newsphysiol Sci 13:331-339, 1998

3. Copper DM, Perchkovsky DV, Hackett TI, Knight DA, Granville DJ, Granzyme K: Activates protease-activated receptor I. Journal-Pore 30:1-14, 2011

4. Dirks BP: Stem cell neurobiology. Neuro Oncolog. Bernstein M, Berger SM (eds). New York Stuttgart: Thieme, 2008:39-44

5. Drews RE, Leung LLK, Tirnaver JS: Approach to the adult patient with a bleeding diathesis. UpToDate 1-20, 2013

6. Drews RE, Schrier SL, Landow JA: Hematologic consequences of malignancy anemia and bleeding. UpToDate 1-23, 2013

7. Falanya A, Lee YYA, Streift BM, Lyman HG: Anticoagulation of the treatment of venous thromboebolism in patients with cancer. In: Perez A (ed), Cancer Care in Minority Populations. American Society of Clinical Oncolog 2008:258-268

8. Farhadi FH, Rutka TJ: Molecular markers and pathways in brain tumorigenesis. Bernstein M, Berger SM (eds). Neurooncology. Thieme, 2008:32-38

9. Fay PW, Leung KLL, Tirnaver SJ: Thrombotic and hemorrhagic disorders due to abnormal fibrinolysis. UpToDate 1-18, 2013

10. Gerber DE, Grossman SA, Streiff MB: Management of venous Thromboembolism in patients with primary and metastatic brain tumors. Journal of Clinical Oncology 24(8):1310-1317, 2006

11. Glick PR, Lichtor T: Immunobiology and immune therapy. Bernstein M, Berger MS (eds). Neuro-oncology. New York Stuttgart: Thime, 2008:213-224

12. Goh KY, Tsoi WC, Feng CS, Wikham N, Poon WS: Haemostatic changes during surgery for primary brain tumors. J Neurol Neurosurg Psychiatry 63(3):334-338, 1997

13. Gottlieb AL, Lanqille BL, Wong MK, Kim DW: Structure and function of the endothelial cytoskeleton. Lab Invest 65(2):123137, 1991

14. Junge CE, Lee CJ, Hubbard KB, Zhang Z, Olson JJ, Hepler JRi, Brat DJ, Traynelis SF: Protease-activated receptor-1 in the human brain: Localization and functional expression in astrocytes. Exp Neurol 188(1):94-103, 2004

15. Kassam AB, Horowitz M, Chang YF, Peters D: Altered arterial homeostasis and cerebral aneurysms: A review of the literature and justification for a search of molecular biomarkers. Neurosurgery 54(5):1199-1212, 2004

16. Kayser-Gatchalian MC, Kayser K: Thrombosis and intracranial tumors. J Neurol 209:217-224, 1975

17. Keles EG, Berger SM: Functional mapping. In: Bernstein $M$, Berger SM (ed), Neuro-Oncology. New-York 2008:126-131
18. Khorana AA, Connoly CG: Assessing risk of thromboembolism in the patient whit cancer. American Society of Clinical Oncology 27(29):4839-4847,2009

19. Kuderer MN, Ortel LT, Francis WC: Impact of venous thromboembolism and anticoagulation in cancer and survival. Journal of Clinical Oncology 27:4902-4911, 2009

20. Levine NM: New antithrombotic drugs. Journal of Clinical Oncology 27(2):4912-4918, 2009

21. Liu L, Freedman J, Hornstein A, Fenton JW, Song Y, Ofosu AF: Binding of thrombin to the G-protein- linked receptor and not to glycoprotein $\mathrm{lb}$, precedes thrombin-mediated platelet activation. Journal of Biological Chemistry 272:1997-2004, 1997

22. Marras CL, Geerts HW, Perry RJ: The risk of venous thromboembolism is increased throughout the course of malignant glioma. American Cancer Society 89(3):640-646, 2000

23. Moffatt JD, Cochs TM: The role of protease-activated receptor-2(PAR2) in the modulation of beating of the mouse isolated ureter lack of involvement of mast cell as sensory nerves. British Journal of Parmacology 128:860-864, 1999

24. Morrison SR, Jarell DA, Schuster MJ: Growth factors and brain tumors. Winn Richard H (ed). Neurological Surgery, Vol: 1b, Philadelphia: Saunders, 1996:725-756

25. Nishi T, Goto T, Takeshima H, Hamada K, Tada K, Saito Y, Kochi M, Karatsu J, Ushio Y: Tissue factor expressed in pituitary adenoma cells contributes to the development of events in pituitary adenomas. Cancer 86(7):1354, 2000

26. Rayland RL, Wagner LD, Huang YP, Som PM, Teal JS, Handler MS: Streaming hypointensity in hemorrhagic glioblastoma multiforme. An illustrative case. Neuroradiology 32(3):241243,1990

27. Rodas RA, Fenstermaker RA, McKeever PE, Blaivas M, Dickinson LD, Papadopoulos SM, et al: Correlation of intraluminal thrombosis in brain tumor vessels with postoperative thrombotic complications: A preliminary report. J Neurosurg 89:200-205, 1998

28. Sarkar A, Chiocca A: Glioblastoma and malignant astrocytoma. Kaye HA, Laws RE (eds). Brain Tumors. Edinburg 384-407, 2012

29. Schin VB, Vanhoutte PM: Endothelium-derived vasoactive factors in thrombosis and hemorrhage. Loscal J, Schafer I (eds). Oxford: Blackwell Scientific Publications, 1994:349-367

30. Van Durme CM, Idima RN, vanGuldener C: Two rare complications of glioblastoma multiforme persistent hiccup and acquired haemophilia. Neth J Med 66(7):286-288, 2008 